\title{
A PROSPECTIVE COMPARATIVE OBSERVATIONAL STUDY ON SAFETY, EFFICACY AND COST EFFECTIVENESS OF INSULIN AND THEIR ANALOGUES
}

\author{
PRUDENCE ATTILADE RODRIGUES*, ANU BALAN, CHARUMATHI PURUSHOTHAMAN \\ PSG College of Pharmacy, Coimbatore 641004, Tamil Nadu, India \\ Email: attilade2016@gmail.com
}

Received: 20 Jul 2017 Revised and Accepted: 06 Jun 2018

\begin{abstract}
Objective: The objective of this study was to compare safety, efficacy and cost effectiveness of insulin and their analogues when compared with human insulin in patients with type-2 diabetes mellitus.
\end{abstract}

Methods: A prospective observational study was carried out in a multispecialty hospital. The inpatients and outpatients from general medicine and endocrinology departments were included in our study for a period of 6 mo. The diabetic profile such as FBS, PPBS, HbA1c and body weight of the diabetic patients at the initial visit and follow up visit was documented.

Results: This study showed a statistically significant reduction in HbA1c, PPBS, and FBS levels from the baseline in insulin analogue users. It was found that, insulin analogue with metformin showed statistical improvement $(\mathrm{P}<0.05)$ in FBS, PPBS, HbA1c as well as body weight and also found to be a cost-effective treatment according to Incremental cost-effectiveness ratio (ICER) decision matrix.

Conclusion: This study concluded that type 2 diabetes patients underlined with the treatment using insulin analogue showed a better glycemic control when compared to human insulin. Metformin was the better OHA option in type-2 diabetes mellitus when compared with sulphonylureas and also metformin showed less weight gain than sulphonylureas.

Keywords: Type-2 diabetes mellitus, Human insulin, Insulin analogue, Glycosylated hemoglobin, Incremental cost-effectiveness ratio

(C) 2018 The Authors. Published by Innovare Academic Sciences Pvt Ltd. This is an open access article under the CC BY license (http://creativecommons.org/licenses/by/4.0/) DOI: http://dx.doi.org/10.22159/ijpps.2018v10i7.21464

\section{INTRODUCTION}

Diabetes mellitus is an emerging health care problem in India. In the present century, about 177 million patients worldwide are affected by diabetes mellitus especially type- 2 diabetes mellitus and it is predicted to rise up to 300 million individuals by 2025 [2]. Diabetes mellitus is a metabolic disease which results in hyperglycemia either because cells do not respond to insulin or the pancreas does not produce enough insulin [3]. To reduce the risk of complications in diabetes mellitus patients, it is essential to control fasting and post prandial blood glucose levels [4]. Maintaining the glycemic level to the normal range has a powerful benefit in preventing various diabetes specified micro vascular complications such as diabetic retinopathy, diabetic neuropathy and diabetic nephropathy.

Initially, oral anti-diabetic drugs are administered at low doses and can be titrated up according to the glycemic control, which can be determined by the HbA1c level [5]. This is indicated for patients with diabetes mellitus who were unable to achieve adequate glycemic control by exercise, diet or antidiabetic drugs [6, 7]. Human insulin and insulin analogues are insulin agents used for the treatment of diabetes mellitus [8]. Insulin analogues were developed in recent decade to overcome the disadvantages of the conventional insulin [9].

Insulin analogues available are rapid acting (insulin lispro, insulin aspart), long acting (insulin glargine, insulin detemir) and premixed analogues (insulin aspart30, insulin lispro30, insulin lispro25). Human insulins available are rapid acting (regular human insulin), intermediate acting (NPH Insulin) and premixed insulin (30\%/70\% regular $/ \mathrm{NPH}, 50 \% / 50 \%$ regular $/ \mathrm{NPH})$ [7, 10]. Modern insulin analogues were designed to aid achievement of better glycemic control while addressing concerns about hypoglycemia and body weight gain [11]. Many of the type-2 diabetic patients benefit greatly from insulin therapy. Delaying initiation of insulin therapy is due to the lack of awareness of disease progression, aversion to injection, patients and physicians concerns about weight gain, hypoglycemia and cost $[11,12]$. Data available on hypoglycemic events in the 24 controlled clinical trials (19 open, unblinded, and 5 double-blind) reported to date with rapid-acting insulin analogues (22 studies with insulin lispro). A significant reduction in the incidence of mild hypoglycemia was observed in 5 of 22 studies (22\%) \{18\}.

Cost effectiveness analysis (CEA) compares different treatment options for achieving the same therapeutic goal. CEA helps to estimate the incremental cost per unit of effectiveness obtained by comparing a new drug with a standard drug. This will guide clinicians regarding how much it costs to obtain an additional case free of the condition. Incremental cost-effectiveness ratio (ICER) indicates the cost per unit of benefit (extra cost per unit of extra outcome) obtained when switching from one treatment to an alternative treatment option. ICER helps us to determine whether the more expensive treatment is cost-effective or not [13].

Most of the increased cost in treating diabetes is due to the complications in diabetes mellitus [9]. Some pharmacoeconomic studies showed that safety and efficacy outcomes of newer insulin analogues decreased the direct and indirect cost of treating diabetes mellitus [14]. Based on various studies, it is estimated that the global cost of diabetes accounts about 2-3\% of the total health care budget of every country [15]. Evidence from pharmacoeconomic data will help the pharmacists, policy makers, and other health care professionals in making decisions based on the use of medication and health care services [16].

\section{MATERIALS AND METHODS}

A prospective observational study was carried out in a multispecialty hospital on the inpatients and outpatients from general medicine and endocrinology departments for a period of $6 \mathrm{mo}$. The study was approved by the institutional human ethics committee with the proposal No: $13 / 202$. Both male and female patients with type-2 diabetes mellitus of $18 \mathrm{y}$ and above having HbA1c of more than $7 \%$, receiving insulin, insulin analogue, oral hypoglycemic agents (OHAs) and willing to participate were included in this study after getting a written consent. The patients with gestational 
diabetes and type- 1 diabetes mellitus, age of less than 18years, patients with only OGLDs and HbA1c of less than $7 \%$ were excluded from our study. The study subjects were examined for their demographics, lab values, co-morbidities, medications, diabetic profile and adverse drug events. The diabetic profile such as FBS, PPBS, HbA1c and body weight of the diabetic patients during the initial visit and follow up visit was recorded. Paired t-test and the student t-test were the statistical tools used to analyze and compare the treatment regimens. All the statistical analysis was done using statistical package for the social sciences (SPSS) software version 19. The cost-effectiveness of the drug was determined using Incremental cost-effectiveness ratio. Costs of drugs were obtained from the Hospital information system (HIS). The effects of the drugs were determined based on the change in the diabetic profile. Report on the cost-effectiveness was done utilizing ICER decision matrix and interpretation was done by ICER quadrant plane.

\section{ICER $=($ Cost of $X-$ Cost of $Y) /($ Effect of $X$-Effect of $Y)$}

Data interpretation: ICER Quadrant plane Data report: ICER Decision matrix

\section{RESULTS AND DISCUSSION}

A total 95 subjects was enrolled in this study. Out of 95 subjects, 50 patients were male and 45 were female. Patients under age group 45-64 were predominant than the other age groups. About 35 patients had a family history of type- 2 diabetes mellitus. The 28 and 67 patients were alcoholics and non-alcoholics respectively. 32 were smokers and 63 were non-smokers. Among the 95 patients, 62 patients were treated with human insulin and 33 patients were treated with insulin analogue. Mean age $( \pm$ SD) for the entire cohort was found to be $56.957 \pm 9.441$. Mean baseline body weight $( \pm S D)$ for insulin analogue users was $65.438( \pm 12.572) \mathrm{kg}$, which was higher than for human insulin users that was $64.446( \pm 9.777) \mathrm{kg}$. Mean $( \pm$ SD) diabetes duration was found to be $10.936 \pm 6.505$ y for the entire population (table 1). Mean baseline HbA1c $( \pm S D)$ for patients using human insulin was found to be $10.159( \pm 2.183) \%$ less than patients using insulin analogues $10.806( \pm 2.246) \%$. Mean baseline FBS and PPBS $( \pm$ SD $\{214.424( \pm 74.120) \mathrm{mg} / \mathrm{dl}$ and 337.818 $( \pm 116.408)\}$ was higher for patients using insulin analogue than human insulin (table 1). Only 6 patients using human insulin showed hypoglycemic episodes.

Table 1: Patient characteristics for the entire cohort and prestudy group $(n=95)$

\begin{tabular}{|c|c|c|c|}
\hline Characteristics & Entire cohort & Human insulin & Insulin analogues \\
\hline n \% & $95(100 \%)$ & $62(65.26 \%)$ & $33(34.74 \%)$ \\
\hline Age & $56.957 \pm 9.441$ & $56.080 \pm 8.832$ & $58.606 \pm 10.434$ \\
\hline Body weight $((\mathrm{kg})$ & $63.486 \pm 10.857$ & $62.446 \pm 9.777$ & $65.438 \pm 12.572$ \\
\hline$B M I(\mathrm{~kg} / \mathrm{m} 2)$ & $24.452 \pm 4.059$ & $24.221 \pm 3.705$ & $24.851 \pm 4.642$ \\
\hline Diabetes duration (years) & $10.936 \pm 6.505$ & $11.232 \pm 6.9091$ & $11.045 \pm 5.1683$ \\
\hline$H b A 1 c(\%)$ & $10.432 \pm 2.218$ & $10.159 \pm 2.183$ & $10.806 \pm 2.246$ \\
\hline$F B S(m g / d l)$ & $203.26 \pm 89.546$ & $197.322 \pm 96.804$ & $214.424 \pm 74.120$ \\
\hline$P P B S(\mathrm{mg} / \mathrm{dl})$ & $304.65 \pm 121.397$ & $287 \pm 121.199$ & $337.818 \pm 116.408$ \\
\hline
\end{tabular}

Values are given in (mean \pm SD)

The entire patients enrolled in this study showed improvement in FBS, PPBS, HbA1c and body weight after 6 mo of therapy. In human insulin users, mean baseline FBS reduced to $140.661 \pm 45.956 \mathrm{mg} / \mathrm{dl}$ (table 2). PPBS reduced to $211.645 \pm 67.376 \mathrm{mg} / \mathrm{dl}$ and $\mathrm{HbA1c}$ reduced to $8.593 \pm 1.757 \%$. Mean body weight in human insulin users not show a greater reduction but a reduction from $62.03 \pm 10.541 \mathrm{~kg}$ to $61.317 \pm 9.697 \mathrm{~kg}$ was observed. In insulin analogue users, a greater reduction for FBS and PPBS was seen (214.424 \pm 74.120 $\mathrm{mg} / \mathrm{dl}$ to $123.303 \pm 33.335 \mathrm{mg} / \mathrm{dl})$ and $(337.818 \pm 116.408 \mathrm{mg} / \mathrm{dl}$ to $194.060 \pm 71.312 \mathrm{mg} / \mathrm{dl})$. Mean HbA1c reduced from $10.806 \pm 2.246 \%$ to $8.492 \pm 1.705 \quad 0.806 \%$ and bodyweight also reduced to $63.359 \pm 12.012 \mathrm{~kg}$ from $65.438 \pm 12.572 \mathrm{~kg}$ (table 2).

Table 2: Diabetic profile-pre and post study groups $(\mathrm{N}=95)$

\begin{tabular}{lllll}
\hline Parameter (mean) & & Entire cohort & Human insulin & Insulin analogue \\
\hline FBS(mg/dl) & Baseline & $203.26 \pm 89.546$ & $197.322 \pm 96.804$ & $214.424 \pm 74.120$ \\
& After6months & $134.63 \pm 42.637$ & $140.661 \pm 45.956$ & $123.303 \pm 33.335$ \\
PPBS(mg/dl) & Baseline & $304.65 \pm 1221.397$ & $287 \pm 121.199$ & $337.818 \pm 116.408$ \\
& After6months & $205.54 \pm 68.905$ & $211.645 \pm 67.376$ & $194.060 \pm 71.312$ \\
HbA1c (\%) & Baseline & $10.43 \pm 2.218$ & $10.159 \pm 2.183$ & $10.806 \pm 2.246$ \\
& After6months & $8.55 \pm 1.724$ & $8.593 \pm 1.757$ & $8.492 \pm 1.705$ \\
Weight(kg) & Baseline & $63.49 \pm 10.858$ & $62.446 \pm 9.771$ & $65.438 \pm 12.572$ \\
& After6months & $62.03 \pm 10.541$ & $61.317 \pm 9.697$ & $63.359 \pm 12.012$ \\
\hline
\end{tabular}

Values are given in $($ mean \pm SD)

This study assists in comparing the outcomes of insulin analogues with human insulin in the treatment of type 2 diabetes mellitus. While comparing human insulin and insulin analogue, later showed a greater mean difference from the baseline after 6 mo of insulin therapy. There was a change in all diabetic profiles (FBS, PPBS, HbA1c) and body weight difference which was statistically significant (all $\mathrm{p}<0.05$ ). Mean difference in PPBS for those patients who received insulin analogue was found to have greater mean difference in PPBS than human insulin users (table 3). A study by Chris G Cameron revealed that insulin analogues were more effective than regular human insulin in the treatment of type 2 diabetes mellitus in adults who required insulin therapy.

The incremental cost effectiveness ratio for insulin analogue was found to be higher. As per the ICER quadrant plane, insulin analogue falls in quadrant I and according to ICER decision matrix, insulin analogue has a high cost and a high effect (table 5, fig. 1 and 2). This shows that Insulin analogue is cost effective than human insulin. A study by Diana I et al. showed that pharmacoeconomic models and retrospective analyses of healthcare databases have consistently shown that treatment with insulin analogues is cost-effective versus other options in the long run. Another study by Palmer AJ et al. showed that quality-adjusted life expectancy (QALE) was 0.66 quality-adjusted life years (QALY) higher in the analogue insulin versus the human insulin group (mean+/-SD) $(7.65+/-0.09$ versus $6.99+/-0.08$ ). Direct lifetime costs were 1654 pounds greater with analogue versus human insulin treatment $(40,876$ pounds $+/-1119$ versus 39,222 pounds+/-1141), producing an incremental cost effectiveness ratio (ICER) of 2500 pounds per QALY gained. 
Table 3: Comparison between human insulin and insulin analogue $(n=95)$

\begin{tabular}{|c|c|c|c|c|c|c|c|}
\hline \multirow[t]{2}{*}{ Parameter } & \multirow[t]{2}{*}{ Groups } & \multirow[t]{2}{*}{$\mathbf{N}$} & \multirow[t]{2}{*}{ Mean } & \multirow[t]{2}{*}{$\begin{array}{l}\text { Std. } \\
\text { deviation }\end{array}$} & \multicolumn{3}{|c|}{$\begin{array}{l}\text { t-test for equality of means } \\
\text { (Equal variances assumed) }\end{array}$} \\
\hline & & & & & t & df & Sig. (2-tailed) \\
\hline \multirow[t]{2}{*}{ FBS Difference } & Human insulin & 62 & 56.66 & 80.501 & -2.100 & 93 & .038 \\
\hline & Insulin analogue & 33 & 91.12 & 67.103 & & & \\
\hline \multirow{2}{*}{ PPBS Difference } & Human insulin & 62 & 75.35 & 114.428 & -2.918 & 93 & .004 \\
\hline & Insulin analogue & 33 & 143.76 & 97.101 & & & \\
\hline \multirow[t]{2}{*}{ HbA1c Difference } & Human insulin & 41 & 1.57 & 1.297 & -2.114 & 69 & .038 \\
\hline & Insulin analogue & 30 & 2.31 & 1.684 & & & \\
\hline \multirow[t]{2}{*}{ Weight Difference } & Human insulin & 62 & 1.13 & 1.968 & -2.205 & 93 & .030 \\
\hline & Insulin analogue & 33 & 2.08 & 2.062 & & & \\
\hline
\end{tabular}

\{N-Number of population, p values are mentioned as Sig. 2-tailed, df-degree of freedom\}, Human insulin in combination with metformin showed significant control in blood glucose and body weight. The mean change after 6 mo showed a statistically significant result (P=<0.05) for all the parameters (table 4).

Table 4: Comparison on treatment regimens with metformin $(n=95)$

\begin{tabular}{|c|c|c|c|c|c|c|}
\hline \multirow[t]{2}{*}{ Parameter } & \multirow[t]{2}{*}{ Groups } & \multirow[t]{2}{*}{ Mean } & \multirow[t]{2}{*}{$\begin{array}{l}\text { Std. } \\
\text { deviation }\end{array}$} & \multicolumn{3}{|c|}{$\begin{array}{l}\text { t-test for equality of means } \\
\text { (Equal variances assumed) }\end{array}$} \\
\hline & & & & t & df & Sig.(2-tailed) \\
\hline \multirow[t]{2}{*}{ FBS Difference } & Mixtard 30/70-Metformin & 51.78 & 78.767 & -2.375 & 75 & .020 \\
\hline & Novomix 30-Metformin & 96.00 & 74.127 & & & \\
\hline \multirow[t]{2}{*}{ PPBS Difference } & Mixtard 30/70-Metformin & 69.02 & 112.193 & -3.418 & 75 & .001 \\
\hline & Novomix 30-Metformin & 158.50 & 101.110 & & & \\
\hline \multirow[t]{2}{*}{ HbA1c Difference } & Mixtard 30/70-Metformin & 1.54 & 1.320 & -2.557 & 57 & .013 \\
\hline & Novomix 30-Metformin & 2.56 & 1.755 & & & \\
\hline \multirow[t]{2}{*}{ Weight difference } & Mixtard 30/70-Metformin & 1.03 & 1.878 & -2.055 & 75 & .043 \\
\hline & Novomix 30-Metformin & 1.99 & 2.074 & & & \\
\hline
\end{tabular}

\{p values are mentioned as Sig. 2-tailed, df-degree of freedom\}

Table 5: ICER determination for insulin analogues verses human insulin in combination with metformin

\begin{tabular}{llllll}
\hline IncrementalCost & Diabetic profile & Incremental effect & ICER & Quadrant & Type \\
\hline Rs.13910.40 & FBS & $44.22 \mathrm{mg} / \mathrm{dl}$ & 314.572 & I & High cost high effect \\
& PPBS & $89.48 \mathrm{mg} / \mathrm{dl}$ & 222.637 & & \\
& HbA1c & $1.02 \%$ & 13637.64 & \\
\hline
\end{tabular}

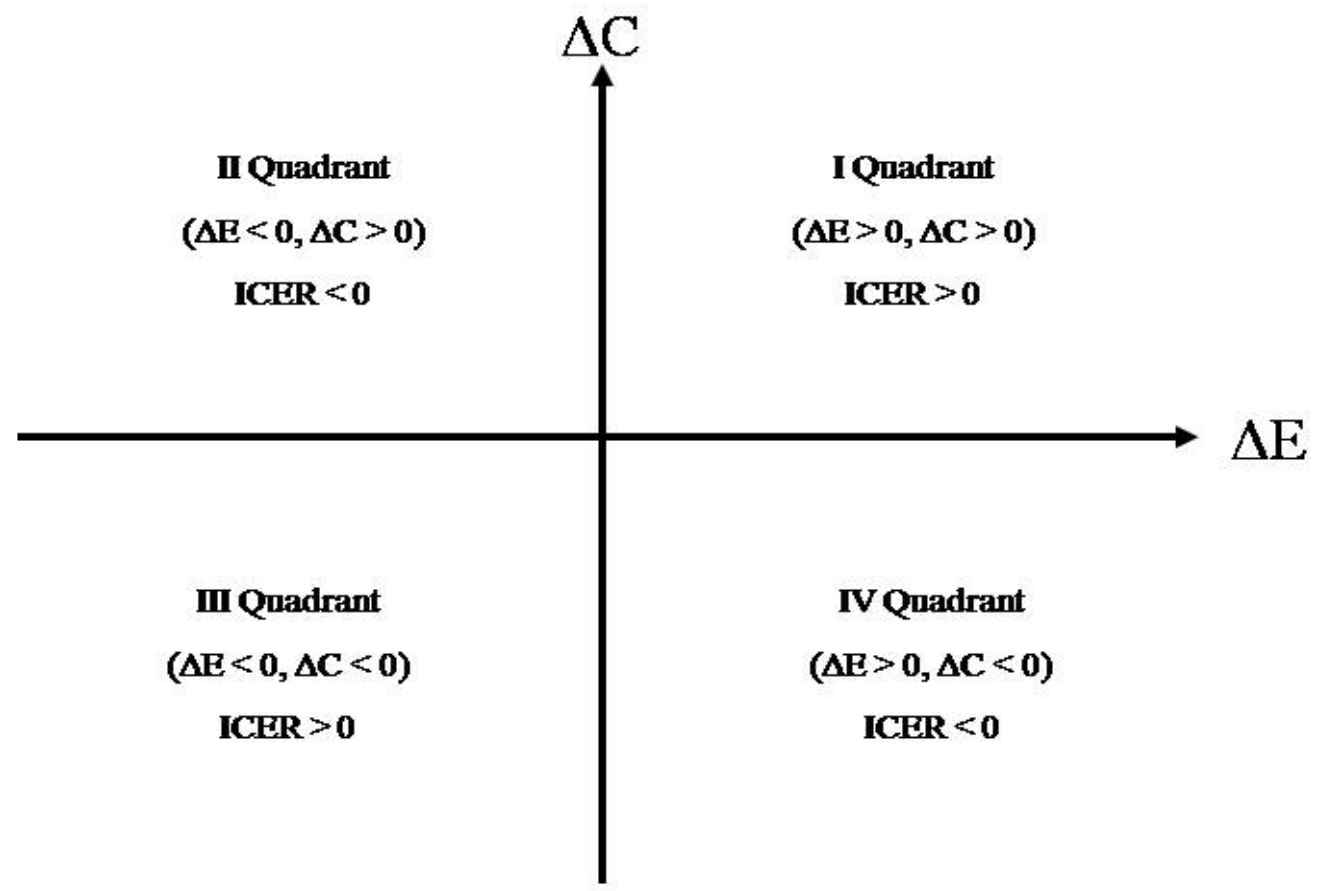

Fig. 1: Incremental cost effectiveness ratio quadrant plane 


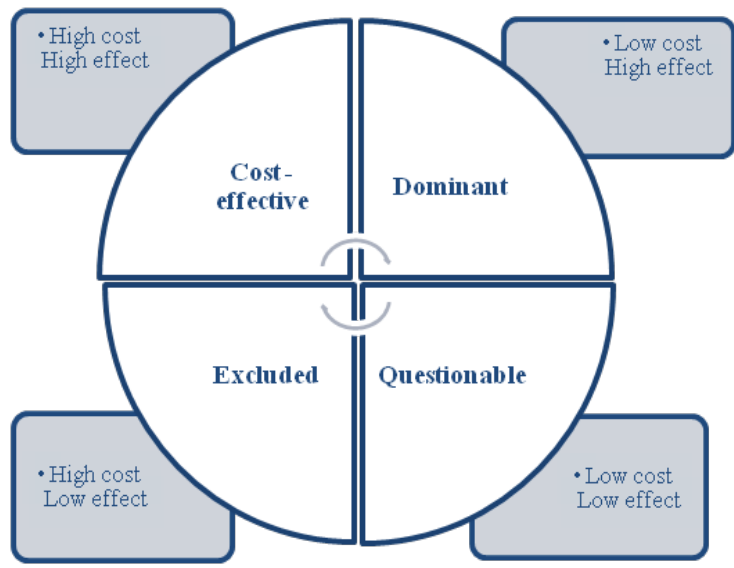

Fig. 2: Incremental cost effectiveness ratio decision matrix

\section{CONCLUSION}

This study concluded that type 2 diabetes patients underlined with the treatment using insulin analogue showed a better glycemic control when compared to human insulin. Metformin was the better OHA option in type- 2 diabetes mellitus when compared with sulphonylureas and also metformin showed less weight gain than sulphonylureas. Hypoglycemic episodes were not reported among patients using insulin analogue unlike for human insulin users. Though it was found that the cost of human insulin was less when compared to insulin analogue, the effectiveness of insulin analogue in lowering FBS, PPBS, HbA1c was better than human insulin. According to the ICER quadrant plane and decision matrix, insulin analogue was found to be cost-effective than human insulin. Thus insulin analogue therapy proved to be a safe, effective and costeffective treatment option in type- 2 diabetes mellitus.

\section{LIMITATIONS}

The study was done for a limited period ( 6 mo duration) of time so difficulty in getting accurate blood glucose level measurement by means of HbA1c. So these types of studies can be done for long time period.

\section{AUTHORS CONTRIBUTIONS}

Authors have no any conflict of interest

\section{CONFLICTS OF INTERESTS}

There is no conflict of interest declared

\section{REFERENCES}

1. Diana I Brixner, Carrie Mc Adam-Marx. Cost-effectiveness of insulin analogs. Am J Manag Care 2008;14:766-75.

2. Vasiliki Valla. Therapeutics of diabetes mellitus: focus on insulin analogues and insulin pumps. Exp Diabetes Res 2010;10:1-14.

3. American Diabetes Association, diagnosis and classification of diabetes mellitus. Diabetes Care 2009;3:62-7.

4. Anil Kapur. Economic analysis of diabetes care. Indian J Med Res 2007;125:473-82.

5. Krentz AJ, Bailey CJ. Oral antidiabetic agents current role in type 2 diabetes mellitus. Drugs 2005;65:85-411.

6. Canadian agency for drugs and technologies in Health. Rapidacting insulin analogues for the treatment of diabetes mellitus. Meta-analyses of Clinical Outcomes; 2008.

7. Sumeet R Singh, Fida Aahmad, Avatar Lal, Changhuaa Yu, Zemi Bai, Heather Bennett. Efficacy and safety of insulin analogues for the management of diabetes mellitus. A meta analysis: CMAJ 2009;180:385-97.

8. Hirsch IB. Insulin analogues. N Engl J Med 2005;352:174-83.

9. Bengt Jonsson. The Economic impact of diabetes. Diabetes Care 1998;21:7-10.

10. Joshi S, Joshi P. A review of insulin and insulin regimens in type 2 diabetes. SA Fam Pract 2009;51:97-102.

11. Korytkowski M. When oral agents fail: practical barriers to starting insulin. Int J Obes Relat Metab Disord 2002;26:18-24.

12. Marre M. Before oral agents fail the case for starting insulin early. Int J Obes Relat Metab Disord 2002;26:25-30.

13. Antonieta Medina Lara, Rubbben Mujica Mata, Dyfrig Hughes. Approaches to pharmcoeconomic analysis. In: Tom Walley, Alan Haycox, Angela Boland. Pharmacoeconomics. Churchill Livingstone; 2004. p. 101-25.

14. Chris G Cameron, Heather A Bennet. Cost effectiveness of insulin analogue. Diabetes Mellitus. CMAJ 2009:180:400-7.

15. American Diabetes Association. Economic costs of diabetes in the U. S. in 2002. Diabetes Care 2003;26:917-32.

16. Diana I Brixner, Carrie McAdam. Cost effectiveness of insulin analogues. AJMC 2008;11:766-75.

17. Palmer AJ, Valentine WJ, Foos V, Lurati F, Smith I, Lammmert $M$, Roze S. An economic assessment of analogue basal-bolus insulin versus human basal-bolus insulin in subjects with type 1 diabetes in the UK. Curr Med Res Opin 2007;23:895-901.

18. Lutz Heinemann. Hyppoglycemia and Insulin analogues. J Diabetes Its Complications 1999:13:105-14. 